First publ. in: Flavins and Flavoproteins, Proceedings of the 10th Internat. Symposium 1991, pp. 27-32

\title{
IONISATION PROPERTIES OF REDUCED, 1,5-DIHYDROFLAVIN, RATES OF N(5)-H EXCHANGE WITH SOLVENT
}

\section{S. Ghisla*}

Faculty of Biology, University, D-7750 Konstanz, FRG

P. Macheroux $\neq$, Ch. Sanner and H. Rüterjans,

Inst. Biophys. Chem. University, D-6000 Frankfurt, FRG

łpresent address: Department of Biol. Chem, The Univ. of

Michigan, Ann Arbor, Mi. 48109 USA)

F. Müller,

Sandoz, Agro Ltd, $\mathrm{CH}-4002$ Basel

Introduction

Fully reduced flavin has primarily three functions at which ionisations of biochemical relevance occur:
A) $\mathrm{N}(1)-\mathrm{H}, \mathrm{pK} 6.5-6.7$
B) $\mathbf{N}(3)-\mathrm{H}, \mathrm{pK}>12$.
C) $\mathbf{N}(5)-\mathrm{H}$ which can

C1) protonate or

C2) deprotonate at low or high $\mathrm{pH}$ values.

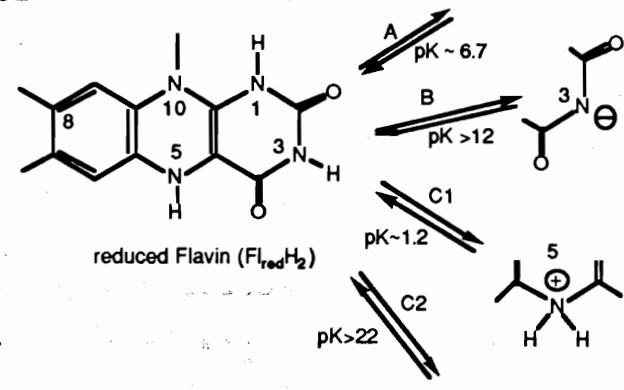

Scheme 1 Ionisations of fully reduced flavin.

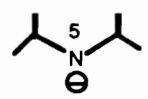

A) The importance of the $\mathrm{N}(1)-\mathrm{H}$ ionisation has long been recognized. It strongly influences the reactivity of the reduced molecule, in particular towards oxygen. A shift of this pK also reflects changes in the redox state of the isoalloxazine [1].

B) The ionisation of $\mathrm{N}(3)-\mathrm{H}$ does not appear to have a major role in influencing the catalytic properties of the flavin. In some cases, e.g. with oxidized glycollate oxidase, the $\mathrm{pK}_{\mathrm{a}}$ of $\mathrm{N}(3)-\mathrm{H}$ is lowered from $\sim 10$ to $\sim 6.7$ due to the interaction with the 
protein [2]. Whether a similar interaction occurs between the reduced flavin and the protein is not known. 15N-NMR measurements at high $\mathrm{pH}(10-12)$ [3] give a $\mathrm{pk}_{\mathrm{a}}>12$ for the reduced flavin $\mathrm{N}(3)-\mathrm{H}$, and with all proteins studied so far, this function appears not to be ionized [4].

C) $\mathrm{N}(5)-\mathrm{H}$ does not have a $\mathrm{pK}$ in or near the physiologically relevant range. However, the $\mathrm{N}(5)$ position is directly involved in the uptake and release of redox equivalents. Its electronic configuration undergoes the largest changes $\left(\mathrm{sp}^{2} \rightarrow \mathrm{sp}^{3}\right)$ during the transition between the oxidized and the reduced state, i.e. during catalysis. In particular, it can serve as the acceptor of the hydrogen bound to the substrate $\alpha$-carbon:

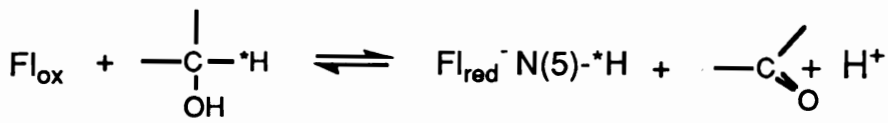

Since $N(5)-H$ has been found to exchange with solvent [5], the mechanism(s) of this exchange is of biochemical importance.

Dudley and coworkers [6] estimated the $\mathrm{pK}_{\mathrm{a}}$ for the protonation of $\mathrm{N}(5)-\mathrm{H}$ as $<0$ (C1 scheme 1), however, no experimental evidence was provided, and this value has been propagated unchallenged in the literature. We have measured a pk value of $\sim 1.2$ by. monitoring the spectral changes of the reduced species as a function of $\mathrm{pH}$ (cf figure 1): Protonation occurs at position $\mathrm{N}(5)$ as deduced from the close similarity of the spectra of protonated reduced flavin and those of $N(5)$-dialkylated species reported earlier [7].

On the other hand, deprotonation of $\mathrm{N}(5)-\mathrm{H}$ yields anionic $\mathrm{N}(5)$ (C2, scheme 1), which has been proposed to be a catalytic intermediate formed upon reaction of flavocytochrome $b_{2}$ with lactate [8]. This would confer a particular importance to this ionisation. The chemical shift of ${ }^{15} \mathrm{~N}$ is correlated with the strength of an $\mathrm{N}-\mathrm{H}$ bond $i . e$. to the $\mathrm{pK}_{\mathrm{a}}$ value as is shown in figure 2 . We have employed this correlation to estimate the $\mathrm{pK}_{\mathrm{a}}$ 


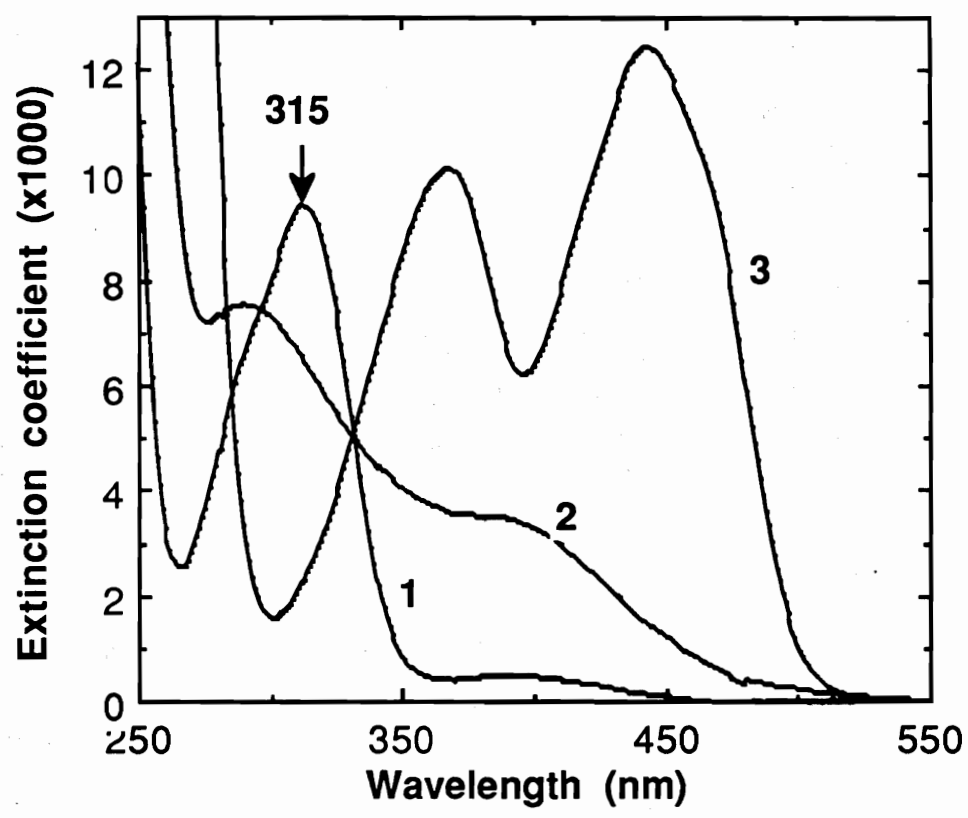

Figure 1: Absorption spectra of neutral and cationic reduced flavin, and of (neutral) oxidized flavin as comparison. An aqueous solution of 3-methyllumiflavin $\left(\sim 3 \cdot 10^{-5} \mathrm{M}\right)$ (curve 3 ) was irradiated in the presence of EDTA $(0.03 \mathrm{M})$ at $\mathrm{pH} 5$ to yield neutral reduced flavin, curve (2). To this, perchloric acid was added anaerobically to yield a $1 \mathrm{M}$ solution. The resulting spectrum, (curve 1 ), is corrected for dilution and for the presence of traces of cationic flavin radical. Whether the residual absorbance at $\sim 400 \mathrm{~nm}$ belongs to the chromophore of cationic reduced flavin or to the presence of traces of protonated oxidized flavin cannot be determined.

of $\mathrm{N}(5)-\mathrm{H}$ using the chemical shift of ${ }^{15} \mathrm{~N}(5)$ in reduced flavin. The $\mathrm{pK}_{\mathrm{a}}$ of $\mathrm{N}(5)$ can also be estimated from the linewidth of the NMR-resonance. Reduced flavin $\mathrm{N}(5)-\mathrm{H}$ has been shown to exchange with solvent in a number of cases, e.g. with flavocytochrome $b_{2}$ [5]. The rate of $N(5)-H$ exchange with solvent has been assumed to be very high [10]. We have estimated it from the linewidth of 


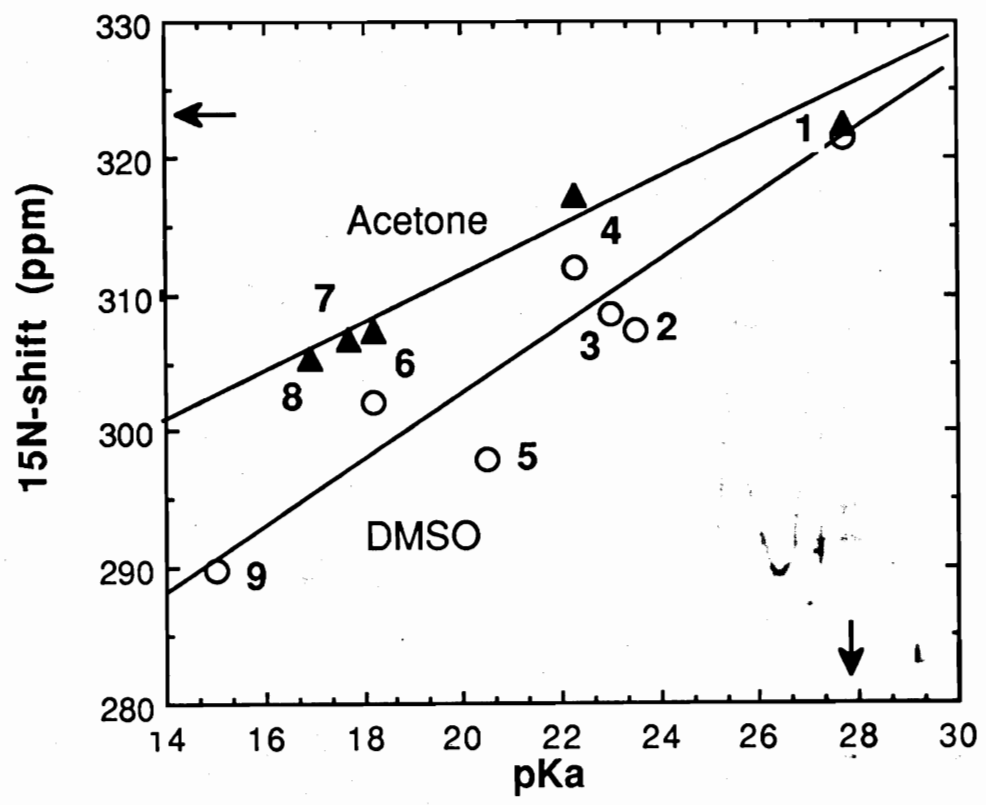

Eigure 2: Estimation of the reduced flavin $\mathrm{N}(5)$ pK from the

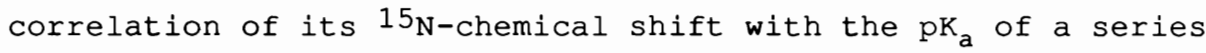
of aromatic amines. The values are from [3,9-11] (nitromethane as reference). The compounds are: 1: aniline, 2: 2-azaaniline; 3: 4-cyano-; 4: 4-aza-; 5: 2,6-diaza-; 6: 4-nitro-; 7: 2-nitro; 8: 4-chloro-2-nitro-; and 9: 2,3-dinitroaniline. Horizontal and vertical arrows: chemical shift of $15_{\mathrm{N}}(5)-\mathrm{H}$ in reduced flavin $[3,10,11]$ and value estimated for the $\mathrm{N}(5)-\mathrm{H} \mathrm{pK}_{\mathrm{a}}$.

the ${ }^{15} \mathrm{~N}(5)$ NMR resonance between $\mathrm{pH} \quad 6$ and 11 . It reaches $a$ minimum around $\mathrm{pH} 9.5$, and, quite interestingly, the rate of exchange is not affected by the ionisation at $N(1)$. This should be compared to the finding, that the ${ }^{15} \mathrm{~N}$-chemical shift of $\mathrm{N}(5)$ in reduced flavin also is not altered by deprotonation at $N(1)$ [7-9]. Both findings are somewhat unexpected and will be ... discussed elsewhere [3]. From the rates of exchange the $\mathrm{pK}_{\mathrm{b}}$ and $\mathrm{pK}_{\mathrm{a}}$ values of $\mathrm{N}(5)-\mathrm{H}$ can be estimated as $\sim-1.5$ and $\sim 22$. The latter value is in reasonable agreement with the one derived from figure 2 in view of the difficulties inherent to the deter- 


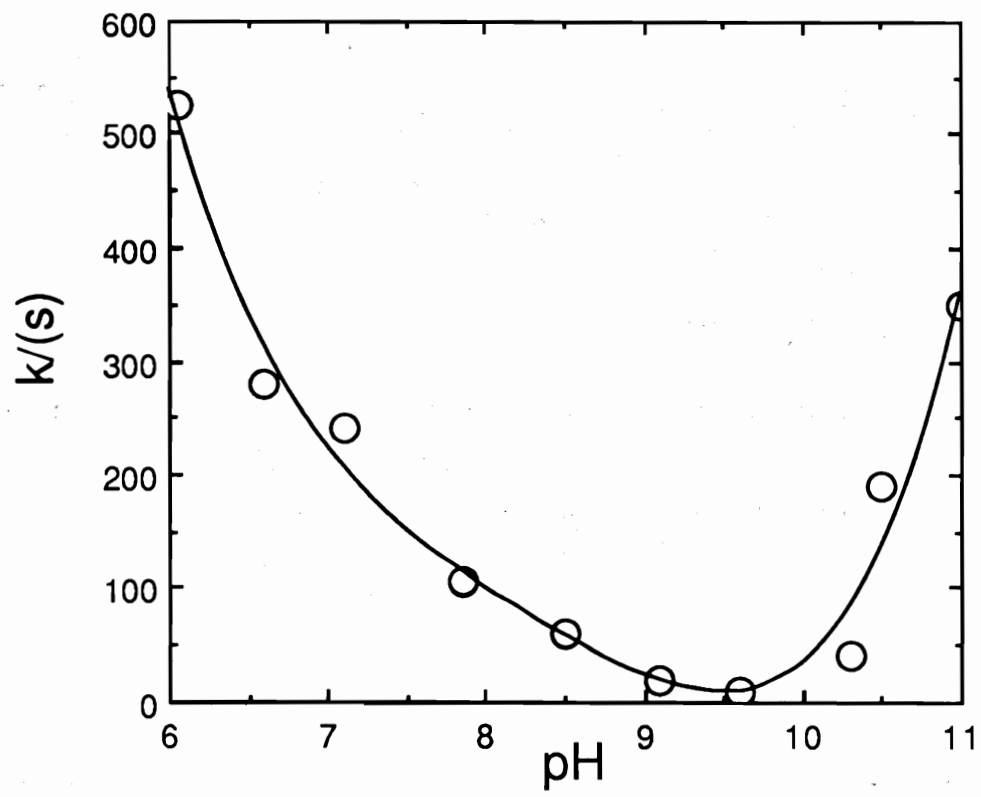

Figure 3:

$\mathrm{pH}$ dependence of the rate of $\mathrm{N}(5)-\mathrm{H}$ exchange. The data were obtained from the line width of the ${ }^{15} \mathrm{~N}-\mathrm{NMR}$ signal of fully reduced flavin. Experimental details to be described elsewhere [3].

mination of the line width of $15_{\mathrm{N}-\mathrm{NMR}}$ signals. Our data suggest that $\mathrm{N}(5)-\mathrm{H}$ does exchange by different mechanisms at high and low $\left[\mathrm{H}^{+}\right]$. At low $\mathrm{pH}$ exchange might be initiated by protonation of $\mathrm{N}(5)-\mathrm{H}$ by $\mathrm{H}_{3} \mathrm{O}^{+}$via the cationic transient (A), (scheme 2), while at high $\mathrm{pH}$ the intermediate or transient species might be anionic (B) and would be formed by interaction with $\mathrm{OH}^{-}$. 


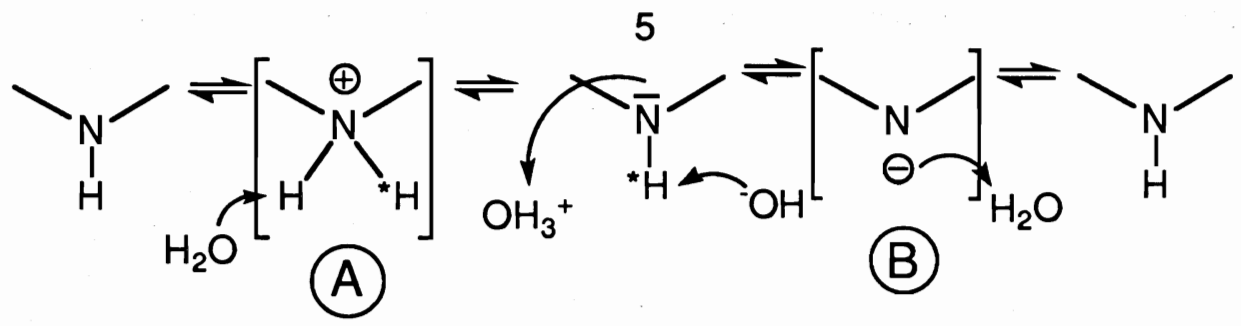

Scheme 2: Modes of exchange of $\mathrm{N}(5)-{ }^{*} \mathrm{H}$ in fully reduced flavin with solvent. Left and right hand sides, modes of exchange at low and high $\mathrm{pH}$.

References

1. Ghisla, S., and Massey, V., (1989) Eur. J. Biochem. 181, 1-17

2. Macheroux, P., Massey, V, Thiele, D.J., Soderlind, E., Lindquist, Y., this volume

3. Macheroux, P. C. Sanner, H. Rüterjans, S. Ghisla and F. Müller, Eur. J. Biochem. manuscript in preparation.

4. Verwoort, J., Muller, F., Mayhew, S.G., vandenBerg, W.A., Moonen, C.T., and Bacher, A., (1986) Biochemistry, 25, 67896799.

5. Walsh, Ch., (1979) in Enzymatic Reaction Mechanisms, p. 366, Freeman \& Comp., New York

6. Dudley, K.H., Ehrenberg, A., Hemmerich, P., and Müller, F., (1964) Helvetica Chimica Acta 47, 1354-1383.

7. Ghisla, S., Hartmann, U., Hemmerich, P., and Müller, F., (1973) Liebig's Ann. Chem. 1388-1415

8 Urban, P., and Lederer, F., (1985) J. Biol. Chem., 258, 11115-11122

9. Witanowski, M., Stefaniak, L., and Webb, G.A. (1981). In Annual Reports on NMR-Spectroscopy, 11B: Nitrogen NMR Spectroscopy (Webb, G.A., ed) Academic Press, London, New York, Toronto, Sydney, .

10. Kawano, K., Ohishi, N., Suzuki, A.T., Kyogoku, Y., and Yagi, K., (1978) Biochemistry, 17, 3854-3859

11. Franken, H.D., Rüterjans, H., and Müller, F., (1984) Eur. J. Biochem., 138, 481-489 